\title{
Copying GP referral letters to patients: the benefits and practical implications
}

\author{
Di Jelley, Dawn Scott and Tim van Zwanenberg, Collingwood Surgery, North Shields, UK
}

\begin{abstract}
The NHS Plan promises that letters about patients will be copied to them as of right. Yet, beyond a few small studies, little is known of the views of clinicians and patients about the process, and few have any experience of it. The aim of this study was to elicit the views of clinicians and patients about the idea of copying general practitioner (GP) referral letters to patients (part one), and to describe the experiences of GPs and patients actually involved in the process (part two). The setting was one health district in the north of England (part one) and three research practices in the same district (part two). A questionnaire survey was used to elicit the views of 214 consultants, $260 \mathrm{GPs}$ and 584 patients (part one), and semi-structured interviews to assess the experience of $11 \mathrm{GPs}$ and 48 patients involved in the process of copying referral letters (part two). The main outcome measures were the perceived and reported benefits and disadvantages of copying referral letters to patients and the practical implications of making this a routine activity. In the first part of the study, replies were received from 148 hospital consultants (70\%), $144 \mathrm{GPs}(55 \%)$ and all the patients in an opportunistic waiting-room sample. Seventy-six of these consultants (55\%) but only 49 of the responding GPs $(34 \%)$ thought that referral letters should be routinely copied to patients. This compares with $499(85 \%)$ of the patients surveyed who were in favour of this in principle. Potential benefits suggested by clinicians included better informed patients and improved communication. There were concerns about making patients anxious and about the difficulty of writing letters that were both comprehensible to patients and informative to colleagues. In the second part of the study, GPs involved in copying letters to patients experienced no major problems in writing letters that patients could understand but which were also fully informative to consultants. There was some increase in administrative workload. A sense of increased openness in the communication process was reported. Patients valued seeing a copy of their referral letter and few admitted to any major problems in understanding its content. In general, they felt better informed about their illness and better prepared for their outpatient appointment -44 patients $(91 \%)$ thought copying letters should become routine practice. In this study, carried out before the NHS Plan was published, a majority of consultants supported, with some reservations, the idea that patients should receive a copy of their GP referral letter. Surveyed GPs anticipated major difficulties in copying letters to patients, and most were not in favour of this becoming routine practice. Patients and GPs actually involved in copying letters reported important benefits but also identified issues which will need to be addressed before copying letters can be effectively implemented as a routine activity.
\end{abstract}

Key words: GP referral letters; NHS plan

\footnotetext{
Address for correspondence: Dr Di Jelley, Collingwood Surgery, Hawkey's Lane, North Shields NE29 0SF, UK.

Email: Di.Jelley@gp-A87004.nhs.uk
} 


\section{Introduction}

Relationships between health professionals and patients are shifting away from paternalism towards greater partnership (Coulter, 1999). This change has been driven not only by public concern about doctors' behaviour, heightened by the recent highly publicized cases of malpractice (Smith, 1999), but also by patients' desire to be more involved in the management of their illness (Jadad, 1999). Clearly, this transition needs to be underpinned by good communication, but there are still misunderstandings between GPs and their patients. Britten et al. argue that communication problems are almost always associated with a lack of patient participation in decision making. They suggest that an interactive and shared approach to the consultation is most likely to elicit and incorporate patients' agendas (Britten etal., 2000). Patient satisfaction is known to increase with such a patient-centred style of consulting (Kinnersley et al., 1999), and patients now have more access to medical information enabling greater involvement in decisions about their health and health care (Ferguson, 2000; Hardy et al.,1999). Finally, most complaints about doctors are known to centre on communication difficulties (Meryn, 1998) and this lesson has been reinforced yet again by the findings of the Bristol Public Inquiry (DoH, 2001). Indeed, in anticipation of one of the recommendations in the Bristol Inquiry report, the NHS plan (for England) promises that 'letters between clinicians about an individual patient's care will be copied to the patient as of right' (DoH, 2000).

Several small studies, including the pilot of this project (Jelley and van Zwanenberg, 2000) have shown that patients value having copies of their clinic or referral letters (Asch et al., 1991; Tattersall, 1989), or hearing the letter dictated in front of them (Lloyd, 1997). In a survey of 420 patients referred to outpatient clinics, involvement of patients in the referral-making process was associated with increased satisfaction with their outpatient consultation (Greenhow et al., 1998). (Hamilton et al., 1999) however, found no difference in outpatient clinic attendance rates in patients sent a copy of their GP referral letter.

Copying correspondence to patients as a routine would represent a major change in behaviour for most clinicians working in the NHS. This study, which was undertaken before publication of the
NHS plan, had two main aims. The aim of the first part was to elicit the views of consultants, GPs and patients on the idea of copying GP referral letters to patients. In the second part the aim was to describe the experiences of a smaller group of GPs and patients actually involved in copying and receiving copies of referral letters.

\section{Method}

\section{Part one}

The views of hospital consultants, GPs and patients were elicited using questionnaire surveys. No previously validated questionnaires were available so draft versions were devised and piloted. The questionnaires required the respondent to state whether they thought GP referral letters should be copied to patients routinely. GP and consultant responders were also invited to list potential benefits and disadvantages of the process, and to identify categories of patients who might need to be excluded from receiving copy letters. The consultant questionnaire included space for comments relating to any experience of copying clinic letters to patients. The study populations consisted of an opportunistic waitingroom sample of 585 patients attending the three research practices, all 260 GPs in one health authority district in the urban north east of England and all the 214 consultants in the same district who receive outpatient referrals directly from primary care.

\section{Part two}

Twelve GPs in the three research practices in the same health district agreed to send a copy of their referral letter to all patients (up to a total of 200 across the three practices) referred to a hospital consultant, psychologist or counsellor between February and April 2000. The three practices were visited by the research team to explain the purpose of the study and to give each GP and typist a study folder. The GP folder contained advice on how to explain the study to patients, written consent forms, and sheets for doctors to record the reasons for excluding any patients from the study and to keep details of any patient contact occurring directly in response to the patient receiving the copy letter. These records were discussed at the follow-up interviews. Typists' folders provided a proforma to record additional time spent on study patients' letters, and to list biographical data on all study patients and the speciality to which they 
had been referred. Patients were asked to participate by agreeing to receive a copy of their referral letter and to take part in a follow-up telephone interview. A total of 200 patients were recruited to ensure that all the GPs had experience of referring several patients within the study period. A purposive sample of 40 patients, to include a range of age groups and hospital specialities, was selected from the 200 and followed up by a semi-structured telephone interview to find out their views on the benefits and disadvantages of receiving a copy of their referral letter. After 40 interviews it was felt that the point of saturation of the data had been reached - and a further eight interviews were carried out to check that no new responses were forthcoming. The interview schedule was based on categories derived from the pilot study (Jelley and van Zwanenberg 2000) and refined after analysis of six exploratory interviews with patients given a copy of their referral letter prior to this study commencing. Data from these patients were not included in the final analysis. Telephone interviews were recorded in writing whilst the call was in progress including verbatim quotes, and patients were encouraged to express their views as fully as possible. Participating GPs were also interviewed, using a semi-structured schedule in which they were particularly encouraged to identify any difficulties that had arisen as a result of copying letters to patients and to discuss the reasons for excluding patients from the study as recorded in their study folders. All these interviews were carried out by one researcher (DS), and tape recorded and transcribed. Data from both parts of the study were analysed and coded independently by two of the research team (DJ and DS) to identify key issues, concepts and themes using an inductive coding process as described by Bowling (1997). The analyses were then compared and joint analytical categories agreed by the research team.
Pre-coded data from the questionnaires was summarized and analysed using SPSS.

\section{Results}

The total numbers of clinicians and patients participating in both parts of the study are summarized in Table 1.

\section{Part one}

\section{The questionaire survey of consultants, GPs and patients}

Responses were received from 148 consultants $(70 \%), 144$ GPs (55\%) and from all the waitingroom questionnaires distributed. Eighty-five consultants (55\%), 49 GPs (34\%) and 499 patients $(85 \%)$ believed that referral letters should be routinely copied to patients. Responding clinicians cited a range of potential benefits and disadvantages that might arise from copying referral letters and these are summarized in Tables 2 and 3 . The main suggested benefits were the increase in patients' knowledge of their condition and more open and equal communication between clinicians and patients. 'There is a great need for patients to have some record of their reason for referral It would often make the initial consultation easier and improve take up of advice given.' (Gastroenterologist - respondent no. 5)

However, many reservations were voiced - 230 of the responding consultants and GPs (90\%) mentioned at least one concern about routinely copying referral letters to patients. Thirty-four consultants $(23 \%)$ and 46 GPs $(32 \%)$ were concerned that receiving a copy letter would increase patients' anxiety, especially where a tentative diagnosis of

Table 1 Summary of participants in both parts of the study

\begin{tabular}{|c|c|c|c|c|}
\hline & Study & Number in sample & $\begin{array}{l}\text { Response } \\
\text { rate/percentage } \\
\text { interviewed }\end{array}$ & $\begin{array}{l}\text { Percentage in favour of } \\
\text { routinely copying referral } \\
\text { letters to patients }\end{array}$ \\
\hline Part 1 & Questionnaire Survey & $\begin{array}{l}214 \text { consultants } \\
260 \mathrm{GPs}\end{array}$ & $\begin{array}{l}148(70 \%) \\
144(55 \%)\end{array}$ & $\begin{array}{l}85(55 \%) \\
49(34 \%)\end{array}$ \\
\hline Part 2 & $\begin{array}{l}\text { GP and patient } \\
\text { interviews }\end{array}$ & $\begin{array}{l}12 \text { GPs } \\
200 \text { patients }\end{array}$ & $\begin{array}{l}11(92 \%) \\
48(24 \%)\end{array}$ & $\begin{array}{l}11(100 \%) \\
44(91 \%)\end{array}$ \\
\hline
\end{tabular}




\section{Di Jelley, Dawn Scott and Tim van Zwanenberg}

Table 2 Potential benefits of copying referral letters to patients - combined views of consultants and GPs

\begin{tabular}{|c|c|c|c|}
\hline Potential benefits & $\begin{array}{l}\text { Number of GPs } \\
n=144\end{array}$ & $\begin{array}{l}\text { Number of } \\
\text { consultants } \\
n=148\end{array}$ & $\begin{array}{l}\text { Total numbers } \\
n=292\end{array}$ \\
\hline $\begin{array}{l}\text { Patient is more actively involved in the management of } \\
\text { their condition }\end{array}$ & $29(20 \%)$ & $21(14 \%)$ & $50(17 \%)$ \\
\hline Clarifies the reason for the referral to the patient & $52(36 \%)$ & $54(37 \%)$ & $106(36 \%)$ \\
\hline $\begin{array}{l}\text { May improve letter accuracy and overall quality of } \\
\text { referrals }\end{array}$ & $43(30 \%)$ & $23(16 \%)$ & $66(23 \%)$ \\
\hline $\begin{array}{l}\text { Fosters an ethos of openness without hidden agendas } \\
\text { unknown to the patient }\end{array}$ & $28(19 \%)$ & $42(28 \%)$ & $70(24 \%)$ \\
\hline Confirms to the patient that the referral has been made & $46(32 \%)$ & $17(12 \%)$ & $63(22 \%)$ \\
\hline $\begin{array}{l}\text { May improve the patient's knowledge and understanding } \\
\text { of their condition }\end{array}$ & $12(8 \%)$ & $20(14 \%)$ & $32(11 \%)$ \\
\hline $\begin{array}{l}\text { May improve doctor-patient communication and reduce } \\
\text { misunderstandings }\end{array}$ & $11(8 \%)$ & $38(26 \%)$ & $49(17 \%)$ \\
\hline May reduce nonattendance at outpatient appointments & $3(2 \%)$ & $4(3 \%)$ & $7(2 \%)$ \\
\hline
\end{tabular}

Table 3 Potential disadvantages of copying referral letters to patients - combined views of consultants and GPs

\begin{tabular}{|c|c|c|c|}
\hline Potential disadvantages & $\begin{array}{l}\text { Number of GPs } \\
n=144\end{array}$ & $\begin{array}{l}\text { Number of } \\
\text { consultants } \\
n=148\end{array}$ & $\begin{array}{l}\text { Total numbers } \\
n=292\end{array}$ \\
\hline Confidentiality issues for the patient or for third parties & $26(18 \%)$ & $14(10 \%)$ & $40(14 \%)$ \\
\hline Anxiety provoking for patients & $46(32 \%)$ & $34(23 \%)$ & $80(28 \%)$ \\
\hline The content of the letter may become more restrictive & $38(26 \%)$ & $71(48 \%)$ & $109(37 \%)$ \\
\hline $\begin{array}{l}\text { Patients may misinterpret or misunderstand the meaning } \\
\text { of the letter }\end{array}$ & $23(16 \%)$ & $34(23 \%)$ & $57(20 \%)$ \\
\hline $\begin{array}{l}\text { Increased use of resources: time, workload, paper, typing, } \\
\text { postage }\end{array}$ & $52(36 \%)$ & $17(12 \%)$ & $69(24 \%)$ \\
\hline $\begin{array}{l}\text { May harm GP/patient relationship especially if wrong } \\
\text { diagnosis made }\end{array}$ & $16(11 \%)$ & $12(8 \%)$ & $28(10 \%)$ \\
\hline $\begin{array}{l}\text { Patients may expect all information to be copied to them } \\
\text { if letters are }\end{array}$ & $1(1 \%)$ & $7(5 \%)$ & $8(3 \%)$ \\
\hline $\begin{array}{l}\text { May be difficult to include information that could be } \\
\text { harmful to the patient }\end{array}$ & $6(4 \%)$ & $8(5 \%)$ & $14(5 \%)$ \\
\hline
\end{tabular}

a serious illness was being made. Seventy-one consultants (48\%) and 38 GPs $(26 \%)$ were also concerned about the difficulty of writing letters that were both comprehensible and acceptable for patients, and adequately informative for colleagues. There was a fear that a copied letter might exclude sensitive information about issues such as depression, marital problems, and alcohol or drug abuse. Overall, GPs were more negative in their views than consultants, many expressing the fear that copying letters would take time, cost money and bring few benefits. This difference may be partially explained by the fact that 90 consultants $(62 \%)$ had personal experience of copying clinic 
letters on occasions to patients and $31(20 \%)$ had seen patients in outpatients who had a copy of their referral letter - neither situation leading to any reported adverse outcomes.

\section{Part two}

\section{The interviews with participating GPs}

It was only possible to interview 11 out of the 12 participating GPs in the three practices. Table 4 lists some key themes that emerged from the analysis of this interview data, focusing on both the benefits of the process and on practical issues to be addressed if copying letters to patients is to become routine practice. All the GPs interviewed felt, by the end of the study, that copying referral letters could be done routinely, although at the outset some had been uncertain. The most frequently mentioned benefit was the increased openness and trust in their relationship with the patient that came from sharing information. At times this helped the GP see things from the patient's perspective. Knowing that the patient would read the letter made the GPs write it more carefully and accurately. They had to think clearly what information was necessary and useful and how it could be expressed clearly and straightforwardly. Six GPs acknowledged a change in writing style and less use of medical terminology, but they did not feel this affected the quality of information provided to the consultant. Letters might appear less 'technical', e.g., the use of heart attack rather than myocardial infarction, but this was acceptable if it was made clear on the letter that the patient was receiving a copy.

A total of 19 patients was recorded as being excluded from the study. Three patients declined to participate because they did not want to take part in a follow-up interview; five patients were excluded for pragmatic reasons (lack of time to discuss the study); and three were referrals requested by a third party (e.g., optician) which did not require direct contact with the patient. The remaining eight exclusions reflected concerns similar to those raised in the questionnaire survey. Two patients had potentially serious neurological conditions that the GP did not want to discuss with the patient until the diagnosis had been confirmed or excluded. Two children were referred for consideration of possible sexual abuse. This was felt to be too sensitive an issue to share with patients unless confirmed. A further two patients were excluded because of lack of acceptance of a diag- nosis (schizophrenia and dementia). In two cases a history of domestic violence led to exclusion because of the fear that the abusing partner might see the letter. Carers were sent letters in several cases of cognitive impairment, but there were concerns about third-party confidentiality.

The participating GPs reported a small increase in workload, mostly in terms of the time taken in the consultation explaining the study and in dictating the letters with greater thought. However, the study record folders indicated few instances of follow-up consultations or other patient contact directly relating to the letter. The typing staff did report an increase in workload not only from the process of copying the letter and writing a second envelope, but also in checking up on consent where the consent form had not been enclosed with the notes.

\section{The interviews with participating patients}

The 200 patients recruited consecutively represented a spectrum from affluence to deprivation as defined by their postcode. Patients ranged in age from 1 to 91 years old and had been referred to a wide range of specialists. Forty-eight of these patients took part in a semi-structured telephone interview. Some characteristics of the study sample receiving copy letters and the subsample of those that were interviewed are compared in Table 5.

The main benefits and concerns mentioned by patients in the telephone interviews are summarized in Table 6. Overall, the response of the patients interviewed was very positive. Forty-four (91\%) felt that copy letters should be routinely sent to patients. The exceptions that patients suggested in response to an open question (not precoded) were similar to those suggested by the doctors, such as patients with a serious or terminal illness, learning disability, difficult home circumstances or severe anxiety. Forty-two patients $(88 \%)$ said that they understood the content of the letter and considered that it was factually correct, but many of these were concerned that patients with less intellectual ability might find difficulty in understanding the letter. Eleven patients cited some words or statements that they had not understood, mostly medical terminology and especially abbreviations.

Some patients had asked advice from family or friends about the letter and others had clarified meanings at the outpatient appointment or used magazines or the Internet. Three patients had contacted the GP to discuss the letter. One felt too much information 
Table 4 Benefits and practical issues raised in GP interviews

Key themes identified from the interviews

Benefits

Sharing information with patients in the form of copied letters increases openness, equality and honesty in the communication process Improves the clarity and accuracy of the content of the referral letter

The patient knows why they have been referred and can use this information to find out more about their health problem

The patient knows that the referral has been made

The patient can check, and if necessary correct, the information in the letter

The difficulty of writing letters that are comprehensible to patients and sufficiently informative to consultants

The difficulty of knowing whether to include sensitive information such as drug/alcohol/relationship/abuse issues

Maintaining confidentiality if the letter is opened by someone else, sent to the wrong address etc
Quotations illustrating these themes

'It's change in the right direction in terms of doctors and patients being able to share risk and share dilemmas and questions so they actually understand' (Int. 5)

'I think it has benefits for the doctor in that you have to clarify your own thoughts about really why you are referring someone and what message you are giving not only to the consultant doctor, but to the patient. So I think it's a useful process and makes patients more involved In something which is critically their own affair' (Int. 10)

'The majority of patients want to know what is the concern, why you are suggesting a referral, and what's going on. If that is emotionally charged information...l would often talk about a potential malignancy even if it's very rare, breast lump being the more common one. It has to be said. Of course it causes distress but to do the opposite is to give someone a false sense of reassurance or not to prepare the patient for the reason...for them not to understand the reasons behind your decision can't be good for anybody' (Int. 4)

'....we may not be right and if we're not right its better that the patient knows about it because they can tell us......but not for medical legal reasons... they can see that we misunderstood it and can put us right which is fine'(Int. 3)

'...you might want to write a different letter if you're involving the patient. We have had experience of hospital discharge letters which have been copied to patients but have been written in a very technical way that has led to major misunderstandings'(Int. 3)

'There will be cases where you need to use technical jargon because its so precise and understandable by colleagues, and you might need to put in brackets, some sort of explanation' (Int. 5)

'I think the good thing is that you might discuss more about what goes into that letter in the first place which I think is good practice whether you copy the letter or not.... And I think it helps us focus particularly around, you know they don't want previous terminations, pregnancies and that sort of information floating around where they can't control it' (Int. 2) 
Table 4 Continued

\begin{tabular}{|c|c|c|}
\hline & Key themes identified from the interviews & Quotations illustrating these themes \\
\hline \multirow[t]{3}{*}{$\begin{array}{l}\text { Practical issues or } \\
\text { concerns }\end{array}$} & $\begin{array}{l}\text { Extra time and resources including } \\
\text { administrative support and postage }\end{array}$ & $\begin{array}{l}\text { '..think it took marginally more time (letter } \\
\text { writing) but not significantly, and if it was } \\
\text { something that made me think then it was } \\
\text { probably time worth taking ... I think you } \\
\text { have to be more thorough and I'm sure } \\
\text { that's not a bad thing' (Int. 8) }\end{array}$ \\
\hline & $\begin{array}{l}\text { Obtaining and recording informed consent } \\
\text { from patients especially for demented, } \\
\text { under-age, psychotic or learning-disabled } \\
\text { patients }\end{array}$ & $\begin{array}{l}\text { Well I think it is difficult because it is } \\
\text { sometimes important to have third party } \\
\text { information in letters to specialists because } \\
\text { you know that is relevant, but it difficult } \\
\text { 'cos obviously you haven't got their } \\
\text { consent' (Int. 6) }\end{array}$ \\
\hline & $\begin{array}{l}\text { Increasing patient anxiety by mentioning in } \\
\text { letters possible serious diagnoses } \\
\text { especially cancer }\end{array}$ & $\begin{array}{l}\text { 'It could have been anything from an acute } \\
\text { paralysing condition to an underlying } \\
\text { carcinoma to a chronic condition ... } \\
\text { Although he had quite clear and dramatic } \\
\text { symptoms ... I couldn't say to him this is } \\
\text { the possible diagnosis and discuss it in } \\
\text { any intelligent way with him and reassure } \\
\text { him about it' (Int. 1) }\end{array}$ \\
\hline
\end{tabular}

Table 5 Comparison of the age ranges and speciality of all the study patients and the interview sample

\begin{tabular}{lllc}
\hline & $\begin{array}{c}\text { Patients receiving copy letters } \\
n=200\end{array}$ & $\begin{array}{l}\text { Interview sample of patients } \\
\text { receiving copy letters } \\
n=48\end{array}$ \\
\hline \multirow{2}{*}{ Age ranges } & $216^{a}$ & $26(13 \%)$ & $9(19 \%)$ \\
& $17-30$ & $36(18 \%)$ & $9(19 \%)$ \\
& $31-45$ & $53(28 \%)$ & $14(29 \%)$ \\
& $46-60$ & $45(22 \%)$ & $9(19 \%)$ \\
& $61-75$ & $29(14 \%)$ & $4(9 \%)$ \\
Speciality & $11(5 \%)$ & $3(5 \%)$ \\
& $>75$ & $41(21 \%)$ & $8(17 \%)$ \\
& Medical (all specialities) & $9(5 \%)$ & $9(19 \%)$ \\
& Paediatrics & $36(17 \%)$ & $18(37 \%)$ \\
& Obstetrics/Gynaecology & $89(45 \%)$ & $9(19 \%)$ \\
& Surgery (all specialities) & $23(12 \%)$ &
\end{tabular}

aparent not child interviewed.

had been given to a counsellor; another consulted to check if she really had taken antidepressants in the past. A third patient came to discuss the fact that his wife, who had opened the copy letter, had not known about his childhood sexual abuse. He reported that this had been very difficult initially, but that ultimately sharing the information had been helpful. Some patients were surprised at the amount of detail in the letter - one wondered whether it was necessary to include a full past medical history in a referral letter for a hearing aid! Twenty patients (42\%) took the letter with them to the clinic appointment, but only nine actually discussed the letter directly with the consultant. Forty-four patients $(91 \%)$ felt that seeing a copy of the referral letter was helpful. The reasons given, included the value of knowledge as a prompt for question and discussion, better communication and understanding, starting from common ground 'you know what they know', and knowing the referral had actually been made. 
Table 6 Benefits and concerns mentioned by patients in the interview sample

Key themes identified in the interviews
Quotations illustrating these themes

'You felt well informed when you went (to OPA), high blood pressure, the tablets you're on, the GP put all that on and other information that was helpful' (French polisher, male, 57)

'I knew they'd covered everything (in the letter) because when you go to the hospital you tend to forget what you were going to ask, so its useful for reference. It makes you less anxious ...' (Radiographer, daughter of 92-year-old referred woman)

'Keeps them in the picture. The more information they have the better they can act upon it' (DSS manager, male, 57) 'Lets hospital know what you know. There should be no secrets, no constraints' (Builder, male, 52)

'Brilliant in the past you never got to know nought. You walked in the hospital grounds not knowing what to expect' (Mother of 10-year-old referred boy)

Benefits Reduces anxiety

Strengthened GP/patient relationship

'It helps you understand the system a bit better ... the communication between the GP and the consultant'

'You know what was said between the doctors and I feel more comfortable knowing that' (Assistant shop manageress, female, 22)

'It was helpful and interesting. The general impression the GP gave of me was reassuring, that I was otherwise fit' (Ex-telephone supervisor, female, 72)

'Initially read it (copy letter) and felt upset, although seeing how I felt on paper helped. It was therapeutic (pause) yes it helped a lot. It was well described and reflected the consultation and how I was feeling... the letter helped build a better relationship with her (GP)' (Cashier, female, 20)

'It feels easier to discuss things with the GP when they've been open in a letter.' (Unemployed female, 27)

Concerns Difficulty in understanding terminology

'Can't see what the point was unless I can understand what was on there' (Electrician, male, 38)

'The average person in the street doesn't understand the terminology so its not helpful. You should get a concise, summarized letter as most people need someone to translate' (Ex-maintenance electrician, male, 72)

'Depends on what's put in the letter. Explaining a complicated factor to someone with limited knowledge might be difficult, someone with learning disabilities, low intelligence' (Admin. assistant in education, female, 50)

Potential to increase patient anxiety
'Some people may be frightened to know, others will want information, and others won't understand it. Would be dependent on someone's knowledge and anxiety. Maybe if the problem was confidential you wouldn't want your partner to know something - they might open the letter' (Sales rep., male, 55) 


\section{Discussion}

The NHS Plan and the Bristol Inquiry report both state unequivocally that in future patients will receive copies of their general practice and hospital correspondence. This study shows that patients favour this in principle, and that in practice, receiving a copy of their GP referral letter is helpful and informative. The majority of hospital consultants surveyed also favoured the idea, with some caveats and exceptions. A range of potential and realized benefits has been described. GPs involved in copying referral letters all felt it could become routine practice without any great increase in workload or resources. Hamilton's study also suggested that copying referral letters did not significantly add to practice workload (Hamilton et al., 1999). GPs who responded to the postal survey, but who had no experience of copying letters, were more negative in their views, fearing impaired communication with consultants, increased workload and increased patient anxiety.

The views of the hospital consultants, GPs and patients in the first part of this study are likely to be reasonably representative of clinicians and patients elsewhere in the UK, although the low response rate among the GPs does raise questions about reliability. The researcher who carried out the interviews was not otherwise connected to the practice in order to allow patients and GPs to be open in their opinions. The GPs in the participating practices are, however, not wholly 'typical', being members of NHS research practices, and this may limit the generalizability of the study findings in part two.

There is a marked disparity between the negative views of the majority of GPs responding to the survey and the positive response of the participating GPs. GPs in the postal survey raised a large number of potential disadvantages, and could envisage few benefits for doctors or patients. These attitudes may reflect broader negative perceptions about a shift away from doctor-centred consultations. Doctors are socialized throughout their training to be in a position of control and moves towards patient empowerment can be threatening and unwelcome (Hugman, 1991). In contrast, participating GPs felt that sharing information more openly could improve relationships with patients, and they did not see practical considerations such as time and resources as a major constraint. Hospital consultants were more in favour of the idea of copying correspondence to patients than the surveyed GPs, perhaps because they have had more experience of aspects of the process.

Some of the concerns are common among both the surveyed clinicians, and those involved in copying and receiving GP referral letters, and these merit serious consideration. The concerns are about both the content of letters and how they are written. There is a body of literature from psychiatry on 'therapeutic letters' which explores the style of letters that are helpful for patients (White and Epson, 1989). This may be useful for both GPs and consultants who are writing letters that patients will read. The language construction of the letter and the medical terminology used also needs consideration. It may need to be adapted according to the intellectual ability and existing knowledge of the health of the patient. Translation or interpreting facilities may need to be used for those who cannot read English and special provisions such as taperecording may need to be provided for blind or illiterate patients. Patient organizations have also examined the type of information which is most helpful to patients (Coulter et al., 1999) and dialogue with these groups will be essential if this policy is to be implemented effectively (Kravitz and Melnikow, 2001). Consultants clearly appreciate 'nonclinical' information about patients - it will be necessary to discuss with patients whether such information should be included in the referral letter. Tentative diagnoses of a potentially serious nature could alarm patients unless they have been discussed in the consultation. Although this may lengthen the consultation it is likely to improve patient understanding of their condition.

There is also an important issue around confidentiality, especially where the letter contains sensitive information not yet disclosed to other family members. This would need to be discussed and patients might opt not to receive a copy letter at home because of difficulties in maintaining privacy. This is also an issue for patients with learning disabilities, dementia and children under the age of 16 - at what point does the parent or carer have the right to see the referral letter? The question of who makes the decision as to whether a copy letter should be sent is relevant here. However, once it is known that it is national or practice policy to copy referral letters it will be difficult to exclude patients from the process unless they opt out of it themselves. Excluded patients would want to know why they had not received a copy letter. GPs 
will need time and training to explore these matters in more depth and to determine ethical practice. This study suggests that routine copying of referral does not significantly increase the workload, except for the typing staff. Given the current climate, however, GPs may view this as yet another demand on their time and resources with no clearly perceived benefits. Printing and posting a copy of the referral letter is an expense which will need to be recognized.

There is evidence that patient satisfaction depends at least in part on openness and trust in the doctor-patient relationship. Sharing information in the form of referral letters could help develop this openness and mutual understanding, and may be a more practical way of involving patients in their care than costly, interactive computer-based decision support programmes. However, all the study participants, whilst acknowledging the potential benefits, have also articulated concerns about how the process could be implemented. If copying letters is to become routine practice, there is an urgent need to discuss these issues with clinicians and patients in more depth. Without such an approach the implementation of the NHS Plan in this respect may not bring its anticipated benefits.

On a final note, all 10 doctors at Collingwood surgery have now been routinely copying letters to patients for the past two years. A number of other local GPs, having attended meetings about this research project, are now introducing the process into their practices. Monitoring and evaluation of these initiatives will contribute to their more effective wider implementation.

\section{Acknowledgements}

We would like to thank the staff and patients of the three participating practices, Collingwood Surgery, Wallsend Road and Longbenton and Lorraine Marsh who transcribed the tapes and assisted in the data input. This project was supported by the Royal College of General Practice Scientific Foundation and Northumbria Health Care Trust.

\section{References}

Asch, R., Price, J. and Hawks, G. 1991: Psychiatric outpatients reactions to summary letters of their consultations. British Journal of Medical Psychology 64, 3-9.
Bowling, A. 1997: Research methods in health. Milton Keynes: Open University Press.

Britten, N., Stevenson, F.A., Barry, C.A., Barber, N. and Bradley, C.P. 2000: Misunderstandings in GP prescribing decisions: qualitative study. British Medical Journal 320, 1246-50.

Coulter, A. 1999: Paternalism or partnership? British Medical Journal 319, 719.

Coulter, A., Entwistle, R. and Gilber, D. 1999: Sharing information with patients: is the information good enough? British Journal of General Practice 318, 318-22.

Department of Health. 2001: Public inquiry into children's heart surgery at the Bristol Royal Infirmary 1984-1995: Learning from Bristol. London Stationery Office (Cmnd 5207).

Department of Health - Secretary of State for Health. 2000: The NHS Plan: A Plan for Investment, a Plan for Reform. London Stationery Office.

Ferguson, T. 2000: Online patient - helpers and physicians working together: a new partnership for high quality health care. British Medical Journal 321, 1129-32.

Greenhow, D., Howitt, A. and Kinnersley, P. 1998: Patient satisfaction with referral to hospital: relationship to expectations, involvement and information given in the consultation. British Journal of General Practice 48, 911-12.

Hamilton, W., Round, A. and Sharp, D. 1999: Effect on hospital attendance rates of giving patients copy of their referral letter: randomized controlled trial. British Medical Journal 318, 392-94.

Hardy, M. 1999: Doctor in the house: the internet as a source of lay health knowledge and the challenge to expertise. Sociology of Health and Illness 21(6), 820-35.

Hugman, R. 1991: Power in the caring professions. Basingstoke: Macmillan Press.

Jadad, A. 1999: Promoting partnerships: challenges for the internet age. British Medical Journal 319, 761-64.

Jelley, D. and van Zwanenberg, T. 2000: Copying GP referral letters to patients - a study of patients' views. British Journal of General Practice 50, 657-58.

Kinnersley, P., Stott, N., Peters, T. and Harvey, I. 1999: The patient centeredness of consultations and outcome in primary care. British Journal of General Practice 49, 711-16.

Kravitz, R.L. and Melnikow, J. 2001: Engaging patients in medical decision making. The end is worthwhile, but the means needs to be more practical. British Medical Journal 323, 584-85.

Lloyd, B. 1997: A randomized controlled trial of dictating the clinic letter in front of the patient. British Medical Journal $314,347$.

Meryn, S. 1998: Improving doctor-patient communication. British Medical Journal 316, 1922-23.

Smith, R. 1999: All changed, changed utterly. British Medical Journal 316, 1917-18.

Tattersall, R.B. 1989: Informing patients. Lancet 2, 280.

White, M. and Epston, D. 1989: Literate means to therapeutic ends. Adelaide: Dulwich Centre Publications. 